\title{
The impact of digital games on intermediate EFL learners' vocabulary improvement
}

Rahimi Esfahani, Fariba $\bowtie$

Department of English, Faculty of Humanities, Shahrekord Branch, Islamic Azad University, Shahrekord, Iran (Rahimifariba@yahoo.com)

Rafizade Tafti, Mohammad Reza

Department of English, Faculty of Humanities, Shahrekord Branch, Islamic Azad University, Shahrekord, Iran (mrrafizade@yahoo.com)

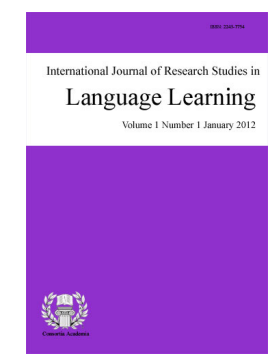

ISSN: 2243-7754 Online ISSN: 2243-7762

OPEN ACCESS

Hajijalili, Mehrnnoosh

Department of English, Faculty of Humanities, Shahrekord Branch, Islamic Azad University, Shahrekord, Iran (23.mehrnoosh@gmail.com) \begin{tabular}{lll} 
Received: 9 December 2018 & Revised: 23 December 2018 & Accepted: 6 January 2019 \\
Available Online: 19 January 2019 & DOI: $10.5861 /$ ijrsll.2019.3013 & \\
\hline
\end{tabular}

\section{Abstract}

This study investigated the effects of using digital games on intermediate EFL learners' vocabulary improvement. To this end, the Oxford Quick Placement Test was given to 62 Iranian EFL learners and based on its results, 40 intermediate students were chosen for the target population of the study. Then, they were divided into two groups- one experimental group and one control group. After that, all the participants were pre-tested and then the treatment was applied. The researcher taught the experimental group by using digital games. Students in the experimental group were taught English vocabulary consisting of the names of different animals, family members, colors and so on through using digital game. On the other hand, students of the control group were deprived of the treatment. They received a traditional teaching instruction. The treatment lasted 15 sessions; the allocated time for each session was 50 minutes. In the last session, the researcher administered the vocabulary post-test to find out the possible effects of the treatment on the participants' vocabulary improvement. The results of paired samples t-test and independent samples t-test showed that there was a significant difference between the post-tests of experimental and control groups. The experimental group outperformed the control group on the post-test. This study has implications for teaching and learning vocabulary.

Keywords: games; digital games; technology-based instruction; vocabulary learning; intermediate EFL learners 


\section{The impact of digital games on intermediate EFL learners' vocabulary improvement}

\section{Introduction}

If language structure makes up the skeleton of language, then it is vocabulary that provides the vital organs and flesh (Harmer, 1991). Horwitz (1988) has discovered that a considerable number of the ESL learners completing her questionnaire-ranging between $25 \%$ and $39 \%$ - either agreed or strongly agreed that the most vital part of learning a foreign language is vocabulary learning. Vocabulary learning has gained much interest in the field of second language acquisition, thus the important point here is how words are learned. In late1980s and 1990s so many studies were developed in this area and researchers tried to find the meaning of effective and efficient in short term and long term vocabulary learning (Cartner \& Nunan, 2002). Some researchers (Yoshii \& Flaitz, 2002) identified vocabulary learning as a pivotal part of each student's life, while other researchers though accept the importance of vocabulary acquisition in language proficiency and academic development; their opinions about how vocabulary should be learned have varied extensively.

Learning vocabulary through games had attained a considerable amount of attention. Donmus (2010) believed that "The estimation of instructive games has been expanding in language training since they help to make language instruction amusing" (p. 1497). As indicated by Donmus (2010), when games and instruction are consolidated, it very well may be educative and training situations can be engaging. The students who learned with the utilization of games, increase inspirational states of mind and can be more propelled while learning. This is a survey of the impacts of utilizing games on learning vocabulary in English as a foreign dialect (EFL). Vocabulary in English is mostly educated outside of context as confined or isolated words; the principle criticism along these lines of instructing is that vocabulary cannot be learnt in segregation (Al Neyadi, 2007).

Activities which include students in considering the words, such as utilizing games enable students to recall the objective words all the more effectively. Learning vocabulary is a diligent work, so endeavor is required to comprehend, create and control the objective words. Games help and urge numerous students to learn target language all the more effortlessly. They additionally assist instructors with creating contexts in which the objective words are valuable and significant; they likewise bring fun for understudies, in this manner enable them to learn and hold new words more rapidly. In other words, game-based learning can make an important context for language learning process. Subsequent to learning and rehearsing new vocabulary through games, learners have the chance to utilize language in a non- stressful manner (Uberman, 1998).

Recreations are beneficial and advantageous in learning vocabulary. They are inspiring in light of the fact that they usually include neighborly rivalry and make agreeable learning condition, so learners have a chance to cooperate. They enhance learners' communicative abilities and they have an opportunity to utilize the target language (Sorayaie- Azar, 2012). Therefore, vocabulary games bring real world context into the classroom, and enhance students' use of English in a flexible, communicative way. The role of games in teaching and learning vocabulary cannot be ignored.

\subsection{Objectives and Significance of the Study}

Learning vocabulary through games is one of the successful and intriguing ways that can be connected in classrooms. In this manner, the goal of the present study was to research the impacts of utilizing digital games on Iranian EFL students' vocabulary learning. Diverse examinations uncovered that amusements are valuable in vocabulary learning since they upgrade students' capacity to retain words, energize students' collaboration, enhance their informative abilities and improve students' inspiration. By utilizing vocabulary games, learners can utilize the language all the more informatively and communicatively. Games likewise can assist the educators with creating settings in which the language is helpful and important. Rohani and Pourgharib (2013) believe that 
The impact of digital games on intermediate EFL learners' vocabulary improvement

with the utilization of games, the instructor can make different settings in which learners need to utilize the language to impart, exchange data and express their very own assessments.

The discoveries of this study are expected to give learners responsibility and the chance of being dynamic physically and rationally. Games are student-focused as opposed to instructor-focused, they effortlessly catch students' eye, increment their cooperation and are amusing to play in the formal scholastic process, and mingle students. What's more, learners gain or create numerous abilities, for example, alternating, working independently and working with others as a group toward a shared objective. The results of this investigation may assist material designers with incorporating more games-based exercises in EFL English materials.

\subsection{Research Question}

The present study was designed to answer the following question:

RQ: Does using digital games have any significant effect on Intermediate EFL learners' vocabulary improvement?

\subsection{Research Null Hypothesis}

The present study tried to test the following hypothesis:

H0: Using digital games does not have any significant effect on Iranian EFL learners' concrete vocabulary improvement.

\section{Theoretical Background}

\subsection{Vocabulary}

The field of second language acquisition has seen the re-sparkling of enthusiasm for one region of vocabulary learning over the most recent 25 years (Meara, 1980). Vocabulary information is regularly seen as a basic device for second language students since an insufficient vocabulary in a second language blocks advantageous communication. On the significance of vocabulary procurement, Schmitt (2000) stresses that "lexical information is fundamental to open fitness and to the securing of a second language" (p. 55). Rubin and Thompson (1994) point to the job of vocabulary in correspondence "One can't talk, read or compose a foreign o jlanguage without knowing a lot of words. Vocabulary is at the heart of mastering a foreign language".

Schmitt (2010) on the significance of vocabulary learning in language utilize states "what might seem to demonstrate is that the span of one`s vocabulary is applicable to one`s execution on any language tests, as it were, that language capacity is to a significant vast degree a component of vocabulary measure" (p. 5). In procedure communication multi-word units (MWUs) are of incredible significance for native speakers and most likely for second/foreign language students. Native speakers are fluent because of having the knowledge of MWUs (or pre-formulated / Formulas / Lexical phrases (Nation \& Meara, 2002).

As indicated by Blachowicz (2007), there are principles for an effective vocabulary instruction, one of which is that "vocabulary learning happens when learners are impressed in words". Firstly, learners learn words all the more adequately when they are read to and when instructor includes them in dialogs (p. 1). Furthermore "vocabulary learning happens when learners are dynamic in finding manners by which words are identified with encounters and to each other", explore demonstrates that when student can make a system of importance for another word in her/his own specific manner, she/he would learn better, that is, the point at which they are dynamic in learning process they are so effective (p. 2). Third one is that "vocabulary learning happens when learners customize word learning". At the point when students utilize their past experiences for adapting new words, they learn more effectively" (p. 3). 
The fourth principle is "vocabulary learning expands on different wellspring of data", when learners ought to learn particular words, they have to utilize different wellsprings of data" (p. 4). Fifth rule is that "vocabulary learning happens when learners gain authority over their own learning", research demonstrates that when learners select vocabulary themselves, they may learn better" (p. 4). The 6th one is that "vocabulary learning happens when learners are helped in creating autonomous systems", by free techniques he/she implies utilizing setting and utilizing lexicon, it very well may be said that when students perused the words in context, their general vocabulary is additionally created (p. 4). The last principle as per Blachowicz (2007), is "vocabulary inclining is dependable when understudies utilize words in significant ways", when students are presented to new words with various kinds of guidance, distinctive profundities and sorts of learning may have been come about" (p. 5).

\subsection{Games and Language Learning}

According to Bardley, Lindstrm, and Rystedt (2010), games are of important advantages as follows: First, games connect all learners in the learning procedure. At the point when learners play games in pairs or groups, they have the chance to perceive and welcome the commitments of others and utilize group building aptitudes. Some classroom games center around individuals working to win against every single other companion in the class. This kind of game functions admirably with learners who are profoundly energetic and focused. Second, games give a chance to coordinated effort as well as participation. Classroom games give a chance to learners to team up and collaborate with one another, while progressing in the direction of a shared objective - winning. In a few games, learners are combined or gathered, which may prompt companion coaching and the utilization of helpful aptitudes with the end goal to win. They may not understand that they are really adapting, but rather they are cooperating towards a shared objective. Third, games give a charming learning knowledge. Making a fun and agreeable learning condition is a substantial initial move toward rousing learners. Research shows that classroom games are powerful strategies that encourage learning.

At last, games help involve all learners, give a chance to cooperate, and give an agreeable learning background" (p. 3). Gairns and Redman (1986) believe that there are three procedures connected in the introducing new vocabulary items. The first is visual methods including pantomime, signals, and Visual, for example, flashcards, Photographs, slate illustrations, wall charts, and regalia. The second one is verbal strategies: (1) utilization of illustrative circumstance, (2) utilization of equivalent word and definition, (3) complexities and alternate extremes, (4) scales, and (5) instances of the type. The last one is interpretation. It is viewed as a snappy, simple, and powerful method for passing on the importance of vocabulary. Gaming is an attribute of human nature, therefore it can be maintained that the narration of gaming goes back to the beginning of the history of human being (Demirbilek, Yilmaz, \& Tamer 2010).

Schlimme (2002) considers that video games provide a context in which applicants can discuss themes and results in order to facilitate their understanding of other notions and can develop children's reading, spelling, and spatial abilities and critical-analyzing techniques. Schlimme (2002) also continues her claims and states that some simulation video games provide players with unfamiliar words which are required with the purpose of succeed in the game, and, consequently, the players' vocabulary levels may increase.

\section{Experimental Background}

To investigate the usefulness of games on language learning some experimental studies have been done. Saffarian and Gorjian (2012) examined the role of PC constructed computer games with respect to encouraging learners' cognitive learning. Their examination researched the impact of the different kinds of instructional conveyance techniques on learners' learning accomplishment. The subjects of their investigation involved 418 EFL instructors and students managing EFL in Iranian organization. The learners' get two distinctive instructional medications: (1) customary computer-assisted instruction (CAI) projects; and (2) a PC based video game. The aftereffects of their examination uncovered that the experimental group who utilized PC games 
The impact of digital games on intermediate EFL learners' vocabulary improvement

performed better than the control group who did not utilize it as a training help in foreign language classroom. In other words, PC games exchanges can assume a facilitative job in teaching and learning second language.

In another research, Efendi (2013) inspected the utilization of games to enhance vocabulary mastery. The objective of his exploration was to depicting the method for "got it game"and "back to the board game" in enhancing vocabulary dominance of the seventh-grade learners. His examination was a sort of classroom action research (CAR) in which the researcher performed as the instructor who drives educating action. In order to gather information, he utilized observation checklist, field note and a test. The members of his examination were 29 learners of seventh grade learners. His examination comprised of four noteworthy advances: arranging, actualizing, watching, and reflecting. The discoveries of the investigation demonstrated that the utilization of "Got It Game" and "Back to the Board Game" with the subjects vocabulary of daily English correspondence, individuals' occupation, and individual consideration and appearance can enhance learners' vocabulary dominance accomplishment.

Correspondingly, Aslanabadi and Rasouli (2013) led an examination on the impact of games on enhancement of Iranian EFL vocabulary information in kindergartens. The purpose of their investigation was to figure out how to help youthful EFL students settle the novel vocabulary in their psyches. The investigation was directed at two kindergartens. They isolated the understudies into the test and control gathering. The test bunch gives an online dialect instructing amusement and the control assemble gives customary educating. The consequence of their investigation uncovered that Games not just convey a good time for students to the class, but they likewise rouse students and enhance their certainty.

Bahojb Jafarian and Shoari (2017) did a quasi-experimental study to examine the effect of game on Iranian young EFL learners' vocabulary learning. Sixty male learners at elementary level participated in the study which lasted one academic semester. There were two groups -one experimental and the other control- with 30 learners in each. The collected data was analyzed by means of SPSS. The findings of the study provided strong support for the effectiveness of the games on word acquisition that might be due to their role in making a relaxed, less stressful, cheerful and enjoyable atmosphere for learning.

\section{Method}

\subsection{Participants}

The sample of the study consisted of 40 Iranian students between the ages of 15 and 17 years old. They were selected among 62 students from a private English Language Institute. All of them were at intermediate level of proficiency in English based on the results of Oxford Quick Placement Test (OQPT). The participants were selected based on non-random sampling; that is, the students were accepted based on a criterion - their scores on the OQPT. All the participants were male and native speakers of Persian. The selected participants were non-randomly divided into two equal groups based on convenience sampling method; one experimental group $(n=20)$ and one control group $(n=20)$.

\subsection{Research instruments}

Oxford Quick Placement Test (OQPT) - The first instrument which was utilized in the present study to homogenize the participants was the OQPT. It could help the researcher to have a greater understanding of what level (i.e., elementary, pre-intermediate, intermediate) her participants were at. This test ha 60 multiple-choice items and based on it the learners whose scores were 0 to 10 were beginners; the leaners whose scores were 11 to 17 were considered as breakthrough; the learners whose scores were 18 to 29 were elementary; those learners whose scores were 30 to 39 were pre- intermediate; the students whose scores were 40 to 47 were intermediate; the learners whose scores were 48 to 54 were considered as the advanced learners and those whose scores were 55 to 60 were very advanced learners. Based on the results of this test, 40 intermediate students were regarded as 
the target participants of the current research.

Researcher-made Vocabulary Pre-test - The second instrument for gathering information was a researcher-made vocabulary pre-test which was designed based on the students' textbook. This test included 40 objective items. The test was piloted on a similar group in another institute whose course book and level were the same. After piloting, the necessary changes and modifications to achieve item characteristics, i.e., item facility, item discrimination, and choice distribution was made in the test. Finally, the test was prepared to use. Its reliability was calculated through KR-21 formula and it was $(r=.987)$.

Researcher-made Vocabulary Post-test - The third instrument which was used in the current research was a researcher-made vocabulary post-test- the modified version of the pre-test. It was administered to determine the effects of digital games on the participants' vocabulary learning. All characteristics of the post-test was similar to the pre-test in terms of time and the number of items. The only difference is that the order of questions and alternatives were changed to wipe out the probable recall of pre-test answers. This test was regarded reliable since it was the modified version of the pre-test.

\subsection{Data Collection Procedure}

First the OQPT was administered in order to manifest the participants' homogeneity in terms of English language proficiency. Forty participants out of 62 were selected for the target population of the present study. The participants were then assigned to two equal groups of 20- one experimental group and one control group. Then, all the participants were pre-tested and then the treatment was practiced. The researcher taught the experimental group using digital games. Students in the experimental group were taught English vocabulary consisting of the names of different animals, family members, colors and so through using digital game. The digital game software that used was called SHAIEx (Sistema Hipermedia Adaptativo para la ensenanza de idiomas en entorno Linex). SHAIEX stands for Adaptive Hypermedia System for the Teaching of Languages at Early Ages built in Linux.

On the other hand, students of the control group were deprived of such kind of the treatment. They received a traditional teaching method. The treatment lasts 15 sessions; the allocated time for each session was 60 minutes. In the first session, the students were homogenized; in the second session, the selected participants were pretested; in 12 sessions the researcher taught vocabulary to the students of the both groups through two different methods. In the last session (fifteen session), the researcher administered the vocabulary post-test to find out the possible effects of the treatment on the participants' vocabulary improvement.

\subsection{Data Analysis}

In order to analyze the data, Statistical Package for Social Science (SPSS) software version 25 was used. Firstly, Kolmogorov-Smirnov (K-S) test was used in order to check the normality of the data. Secondly, descriptive statistics including means and standard deviation were calculated. Finally, to examine the impacts of the treatment on Iranian EFL learners' vocabulary, a paired samples t-test and an independent samples t-test were run. Paired samples t-test was used to compare the pre and post-tests of each group and independent samples t-test was run to compare the experimental group's pre and post-tests to the control group's pre and post-tests.

\section{Results}

In order to analyze the gathered data, the SPSS software, version 25 software was used. Table 1 show that the statistics of scores are normal as the results obtained from using SPSS 25. In this case, the parametric statistics like independent samples t-test and paired samples t-test can be used to get the final results. While, in table 2, the descriptive statistics of both groups is presented. The means of both groups are almost equal. The experimental group's mean score is 11.27 and the control group's mean score is 11.67. This means that both groups were somehow similar at the beginning of the treatment. 
The impact of digital games on intermediate EFL learners' vocabulary improvement

Table 1

One-Sample Kolmogorov-Smirnov Test (Groups' Pre and Post-tests)

\begin{tabular}{llcccc}
\hline \multicolumn{1}{c}{ Statistics } & & Exp. Pre & Exp. Post & Cont. Pre & Cont. Post \\
\hline$n$ & & 20 & 20 & 20 & 20 \\
Normal Parameters & Mean & 11.27 & 15.37 & 11.67 & 12.35 \\
& $S D$ & 1.61 & 1.78 & 1.71 & 1.98 \\
Most Extreme Differences & Absolute & .23 & .16 & .18 & .17 \\
& Positive & .23 & .08 & .18 & .17 \\
& Negative & -.15 & -.16 & -.12 & -.14 \\
Test Statistic & & .23 & .16 & .18 & .17 \\
Asymp. Sig. (2-tailed) & & $.085^{\mathrm{c}}$ & $.137^{\mathrm{c}}$ & $.071^{\mathrm{c}}$ & $.133^{\mathrm{c}}$ \\
\hline
\end{tabular}

Note . Exp. = Experimental, Cont. $=$ Control, Pre $=$ Pre-test, and Post $=$ Post-test.

${ }^{a}$ Test distribution is Normal. ${ }^{b}$ Calculated from data. ${ }^{c}$ Lilliefors Significance Correction.

Table 2

Group Statistics (Pre-test of Both Groups)

\begin{tabular}{llcccc}
\hline & \multicolumn{1}{c}{ Groups } & $n$ & Mean & SD & SE Mean \\
\hline Pretest & Experimental group & 20 & 11.27 & 1.61 & .36 \\
& Control group & 20 & 11.67 & 1.71 & .38 \\
\hline
\end{tabular}

An independent samples t-test was used to show the scores of both groups on the pre-test. Results shows that there was no significant difference in the scores for experimental group $(\mathrm{M}=11.27, \mathrm{SD}=1.61)$ and control group $(\mathrm{M}=11.67, \mathrm{SD}=1.71)$ conditions with $\mathrm{t}(38)=.75, p=.453$. Since the Sig $(.453)$ is greater than .05 , the difference between the groups is not significant at $(p<.05)$. In fact, they performed the same on the pre-test.

Table 3

Group Statistics (Post-test of Both Groups)

\begin{tabular}{llcccc}
\hline & \multicolumn{1}{c}{ Groups } & $n$ & Mean & SD & SE Mean \\
\hline Posttest & Experimental group & 20 & 15.37 & 1.78 & .39 \\
& Control group & 20 & 12.35 & 1.98 & .44 \\
\hline
\end{tabular}

Table 3 showed the descriptive statistics of both groups on the post-test. The experimental group's mean score is 15.37 and the control group's mean score is 12.35 . This means that the experimental group performed better than the control group on the post-test. Results shows that there was a significant difference in the scores for experimental group ( $M=15.37, \mathrm{SD}=1.78)$ and control group $(\mathrm{M}=12.35, \mathrm{SD}=1.98)$ conditions with $\mathrm{t}(38)=5.06$, $p=.000$. Hence, the difference between both groups is significant at $(p<.000)$. In fact, the experimental group outperformed the control group on the post-test.

Table 4

Paired Samples Statistics (Pre and Post-tests of Both Groups)

\begin{tabular}{lllllc}
\hline & Groups & Mean & $n$ & SD & SE Mean \\
\hline Pair 1 & Exp. Post & 15.37 & 20 & 1.78 & .39 \\
& Exp. Pre & 11.27 & 20 & 1.61 & .36 \\
Pair 2 & Cont. Post & 12.35 & 20 & 1.98 & .44 \\
& Cont. Pre & 11.67 & 20 & 1.71 & .38 \\
\hline
\end{tabular}

Table 5

Paired Samples T-test (Pre and Post-tests of Both Groups)

\begin{tabular}{llcccccc}
\hline & Groups & Mean & SD & SE Mean & $t$ & $d f$ & Sig. (2-tailed) \\
\hline Pair 1 & Exp. Post - Exp. Pre & 4.10 & 2.44 & .54 & 7.50 & 19 & .000 \\
Pair 2 & Cont. Post - Cont. Pre & .67 & 1.57 & .35 & 1.91 & 19 & .073 \\
\hline
\end{tabular}

Based on the descriptive statistics in the table 4, the mean scores of the control group on the pre and 
post-tests are 11.67 and 12.35 , respectively. The experimental group's mean scores on the pre and post-tests are 11.27 and 15.37, respectively. In table 5, paired samples t-test was used to compare the pre and post-tests of each group. Since Sig (.000) is less than .05 , the difference between the pre-test and post-test of the experimental group is significant. Since Sig (.073) is greater than .05 , the difference between the pre-test and post-test of the control group is not significant.

\section{Discussion}

In this part the research question "Does using digital games have any significant effect on Intermediate EFL learners' vocabulary learning?" is answered dependent on the outcomes acquired in the tables above. Subsequent to gathering the data, the researcher analyzed them in order to find out the effectiveness of the treatment on the students' vocabulary improvement. The findings showed that the students who received the instruction through digital games had better performance on their post-test compared their pre-test. The results statistically revealed that the experimental group (digital games group) significantly did better on the post-test $(p<.05)$. Therefore, the first null hypothesis of the study "digital games do not have any significant effect on Intermediate EFL learners' vocabulary learning" was rejected. The results showed that digital games appeared to have a greater impact on the vocabulary learning of EFL learners.

The digital games had positive effects on the students' vocabulary knowledge. Learning vocabulary through games had accomplished a ton of consideration. Donmus (2010) believed that "The value of instructive games has been expanding in language training since they help to make language instruction absorbing"(p. 1497). As indicated by (Donmus, 2010), when games and instruction are consolidated, it may be educative and training situations can be entertaining. The students who learned with the utilization of games, increase uplifting mentalities and can be more inspired while learning.

During the twelve sessions of instruction, we tried to apply some new vocabularies used in the game in our speech. They presented what they have experienced while playing game. The learners get deeply in touch with the characters in the game which leads to a sort of interest and motivation. We observed the fact that the ones who played the game were more active and successful learners while doing some related tasks. We concluded that students who played the digital game were more motivated in class and were able to use the new vocabularies of digital games in their speech which were observed by the teacher in the class. Utilizing digital games results to engage learners in acquiring new vocabularies without stress and it makes much more motivated learners in learning process of English vocabularies because, learners apply new vocabularies in their speech in the class.

The findings of the current study are in line with Aghlara and Hadidi Tamjid (2011) who examined the impact of utilizing a digital computer game on advancing Iranian children's vocabulary learning. In the experimental group, the SHAIEx digital game was utilized though in the control group, English vocabulary was instructed through conventional strategies. The outcomes demonstrated that the mean score of the kids in the experimental group was fundamentally higher than those in the control group, showing the beneficial outcome of utilizing digital games in training English vocabulary to kids.

Games could bring fun for learners to the class, and also, they motivated learners and improved their confidence. The findings of the present research are compatible with Aslanabadi and Rasouli (2013) who investigated the effect of games on improvement of Iranian EFL vocabulary knowledge in kindergartens. The result of their study indicated that games motivated learners and increased their confidence.

\section{Conclusion}

Vocabulary has a paramount role in learning English language. Nowadays, educators endeavor to make an intriguing situation for showing vocabulary and not holding a candle to the current situation customary techniques for training which manages paper and pencil. Students in conventional techniques, for example, 
The impact of digital games on intermediate EFL learners' vocabulary improvement

Audio-lingual strategy, impersonate the instructor and rehash each word he/she says. It is repetition learning and not significant inclining. Students don't have any inspiration for going to class since, it is exhausting for them. There isn't any collaboration between students, so it is educator focused. This examination gives new information or perspectives to utilizing advanced recreations in learning vocabularies and this new information can impact on showing techniques vocabularies. It makes new condition for learning in which students can appreciate the learning procedure and their learning level can enhance by utilizing it. Games are not just fun, they can be instructive as well! In computerized recreations-based learning, educators influence utilization of games that to incorporate instruction and computer games. This technique engages students and can be actualized in classrooms for all ages and subjects.

Computerized games assist students with being dynamic members in our 21st technological society. Digital games help encouraging vocabulary learning and simpler retention vocabulary through, connection, inspiration for students and more important learning. As we began saying in this study, our students today are 'digital immigrants' and digital games are very much a part of their lives. The utilization of games in training presently can't seem to create to its maximum capacity and instructive digital games may not be promptly accessible for all learning situations. Notwithstanding, they present us a chance to educate in a way that lines up with the understudy premium, in this way expanding the likelihood of commitment and inspiration which may result in free and important learning. An open door not to be missed!

To summarize, it was discovered that utilizing games and exercises to rehearse vocabulary upgrades students' capacity to obtain words; energizes students' cooperation; and improves their inspiration. Besides, if there is chance to actualize digital games in our instructive framework, students will be all the readier to learn English particularly here English vocabularies. The utilization of digital games in training is one of the variables which make the students intrigued and inspired. Utilizing digital games in the classroom results in better inspiration and it simplifies the learning procedure of EFL students. The learning vocabularies turned out to be more pleasant. It connects with students in such games and there will be low stress condition for learning process.

It tends to be deduced from the findings of this research that digital games positively affect the learning procedure. Utilizing such games in the classroom results in better inspiration and encourages the learning procedure of students and their cognitive development. The learning procedure turns out to be significantly more pleasant and by involving students in such games, the anxieties associated with the learning procedure are definitely diminished. From all the clarification above, it tends to be presumed that the utilizing of games is a great strategy for instructing English vocabulary.

\section{References}

Aghlara, L., \& Tamjid, N. H. (2011). The effect of digital games on Iranian children's vocabulary retention in foreign language acquisition. Procedia-Social and Behavioral Sciences, 29, 552-560. https://doi.org/10.1016/j.sbspro.2011.11.275

Al Neyadi, O. (2007). The effects of using games to reinforce vocabulary learning. In H. C. T. Marifa (Ed.), Action research and initial teacher education in the UAE (pp. 99-107). HCT Press, UAE.

Aslanabadi, H., \& Rasouli, G. (2013). The effect of games on improvement of Iranian EFL vocabulary knowledge in kindergartens. International Review of Social Sciences and Humanities, 6(1), 186-195.

Bahojb Jafarian, R., \& Shoari, E. (2017). The effect of games on Iranian young EFL learners' vocabulary learning. European Journal of English Language and Literature Studies, 5(5), 12-24.

Blachowicz, C. L. Z. (2007). Best practices in vocabulary instruction. Scott Foresman, National Louis University.

Bradley, L, Lindstrm, B., \& Rystedt, H. (2010). Rationalities of collaboration for language learning in a wiki. ReCALL, 22(2), 247-265. https://doi.org/10.1017/S0958344010000108

Carter, R., \& Nunan, D. (2002). The Cambridge guide to teaching English to speakers of other languages. 
Rahimi Esfahani, F., Rafizade Tafti, M. R., \& Hajijalili, M.

Cambridge: Cambridge University Press.

Demirbilek, M., Yilmaz, E., \& Tamer, S. (2010). Second language instructors' perspectives about the use of educational games. Procedia Social and Behavioral Sciences, 9, 717-721.

https://doi.org/10.1016/j.sbspro.2010.12.223

Donmus, V. (2010). The use of social networks in educational computer-game based foreign language learning.

Social and Behavioral Sciences, 9, 1497-1503. https://doi.org/10.1016/j.sbspro.2010.12.355

Efendi, E. (2013). The use of games to improve vocabulary mastery. Journal de Physique, 1(12), 78-84.

Gairns, R., \& Redman, S. (1986). Working with words: A guide to teaching and learning vocabulary. Cambridge: Cambridge University Press.

Harmer. J, (1991). The practice of English language teaching. London: Longman.

Horwitz, E. K. (1988). The beliefs about language learning of beginning university foreign language students. The Modern Language Journal, 72, 283-294. https://doi.org/10.1111/j.1540-4781.1988.tb04190.x

Meara, P. (1980). Vocabulary acquisition: A neglected aspect of language learning. Language Teaching and Linguistics Abstracts, 13, 221-246. https://doi.org/10.1017/S0261444800008879

Nation, P., \& Meara, P. (2002). Vocabulary. In N. Schmitt (Ed.), Introduction to applied linguistics (pp. 35-54). Oxford University Press.

Riahipour, P., \& Saba, Z. (2012). ESP vocabulary instruction: Investigating the effect of using a game oriented teaching method for learners of English for nursing. Journal of Language Teaching and Research, 3(6), 1258-1266. https://doi.org/10.4304/jltr.3.6.1258-1266

Rohani, M., \& Pourgharib, B. (2013). The effect of games on learning vocabulary. International Research Journal of Applied and Basic Sciences, 4(11), 3540-3543.

Rubin, J., \& Thompson, I. (1994). How to become a more successful language learner. Boston, MA: Heinle \& Heinle.

Saffarian, R., \& Gorjian, B. (2012). Effect of computer-based video games for vocabulary acquisition among young children: An experimental study. Journal of Comparative Literature and Culture, 1(3), 44-48.

Schlimme, M. (2002). Video games: A source of benefit or addiction? (Unpublished student paper). Retrieved from http://serendip.brynmawr.edu/bb/neuro/neuro02/web3/mschlimme.html

Schmitt, N. (2000). Vocabulary in language teaching. Cambridge: Cambridge University Press.

Sorayaieazar, A. (2012). The effect of games on EFL learners' vocabulary learning strategies. International Journal of Applied and Basic Sciences, 1(2), 252-256.

Uberman, A. (1998). The use of games: For vocabulary presentation and revision. English Teaching Forum, 36(1), 20-27.

Yoshii, M., \& Flaitz, J. (2002). Second language incidental vocabulary retention: The effect of text and picture annotation types. CALICO Journal, 20(1), 33-58. 